Positive Intergroup Contact, Negative Intergroup Contact, and Threat As Predictors of Cognitive and Affective Dimensions of Prejudice

Christopher L. Aberson

Humboldt State University

Christopher L. Aberson, Department of Psychology, Humboldt State University.

Correspondence concerning this article should be addressed to Chris Aberson, Humboldt State University, Arcata, CA 95521, (707)826-3670, E-mail: cla18@humboldt.edu

Keywords: intergroup contact, prejudice, affective and cognitive dimensions, intergroup threat, intergroup processes

Word Counts: Abstract (151), Text (6433), References (1480), Tables (879)

Number of Tables: 5. Number of Figures: 0 


\begin{abstract}
Research on intergroup contact suggests that contact relates more strongly to affective than cognitive dimensions of prejudice. However, work on these forms of prejudice focuses primarily on positive contact experiences. One goal of this study is to examine whether positive and negative contact experiences differentially predict affective and cognitive prejudice dimensions of prejudice. The second goal is to examine intergroup threats as mediators of contact-prejudice relationships. Results demonstrated that negative contact more strongly predicted cognitive dimensions of prejudice such as stereotypes. Both types of contact were similarly predictive of affective dimensions of prejudice. The mediation of the negative contactprejudice relationship was stronger across all dependent measures than mediation of the positive contact-prejudice relationship. Together these results suggest that either form of contact predicts affective prejudice but negative contact is particularly important in explaining cognitive dimensions of prejudice. Additionally, results suggest an important role for feelings of threat in explaining contact-prejudice relationships.
\end{abstract}




\section{Positive Intergroup Contact, Negative Intergroup Contact, and Threat As Predictors of Cognitive and Affective Dimensions of Prejudice}

Intergroup contact theory proposes that contact with outgroup members, under certain conditions, reduces prejudice toward the outgroup. Large scale meta analyses provide an extraordinary body of support for the relationship between positive outgroup contact and more favorable outgroup evaluations (Pettigrew \& Tropp, 2006) with particularly strong effects for contact via friendship (Davies, Tropp, Aron, Pettigrew, \& Wright, 2011). Additionally, positive contact experiences appear to improve attitudes towards outgroups who are not directly involved in the contact experience (Tausch et al., 2010).

Intergroup threat theory (formerly integrated threat theory) also addresses the relationship between contact experiences and prejudice. Intergroup threat theory however, focuses on negative contact experiences as an antecedent to prejudice and provides a framework for understanding how contact influences prejudice. Several studies conducted from this perspective found negative contact experiences related to unfavorable evaluations across a number of different outgroups (e.g., W. G. Stephan et al., 2002). One of the propositions of the theory is that experiences such as negative contact with outgroup members makes people feel threatened. Feelings of threat in turn promote prejudice and other negative reactions toward the outgroup (W. G. Stephan, Ybarra, \& Morrison, 2009).

Although the contact-prejudice relationship is well established, it appears that this relationship varies based on the dimension of prejudice assessed. For example, in one study, positive contact experiences predicted affective dimensions of prejudice (e.g., emotional reactions) more strongly than cognitive dimensions of prejudice (e.g., stereotypes; Tropp \& Pettigrew, 2005, Study 2). Similarly, the type of contact experience (positive vs. negative) 
produces different effects on prejudice. Negative contact relates more strongly to increased prejudice than positive contact relates to reduced prejudice, an effect termed the positivenegative asymmetry effect (Barlow et al., 2012). The present work extends this research by addressing whether the positive-negative asymmetry effect occurs for both affective and cognitive dimensions of prejudice and explores the role of threats as mediators of these relationships.

\section{Positive and Negative Intergroup Contact and Affective and Cognitive Dimensions of Prejudice}

Measurement of prejudice often focuses on affective or cognitive dimensions of prejudice. Tropp and Pettigrew (2005) defined affective dimensions of prejudice as those broadly addressing emotions or favorability. Emotion measures include anticipated emotions when interacting with an outgroup member. Favorability measures comprise general ratings of positivity (or negativity) felt toward members of the outgroup. The same authors defined cognitive dimensions of prejudice relate to issues such as stereotypes and beliefs about outgroup members. Stereotype measures involve endorsement of negative stereotypes about members of the outgroup. Belief measures focus on aspects such as judgments about the experiences or perspectives of outgroup members. The sections that follow examine how positive and negative contact differentially relate to both dimensions of prejudice.

Positive intergroup contact. Early work on positive contact experiences generally followed the propositions set forth by intergroup contact theory. The basic tenets of intergroup contact theory are that contact experiences that involve equal status, common goals, lack of competition, and are sanctioned by authority reduce prejudice (Allport, 1954). Meta analytic results suggest that contact meeting these conditions relates to reduced prejudice, however, even 
positive contact experiences that do not meet these conditions related to reduced prejudice (Pettigrew \& Tropp, 2006).

With regard to the different dimensions of prejudice, another meta analysis found that affective measures such as emotions and favorability appear more strongly related to contact than cognitive dimensions of prejudice (Tropp \& Pettigrew, 2005, Study 1). Correlational research also supports the contention that positive contact, in terms of the number of outgroup acquaintances and friends, predicts affective dimension of prejudice but does not consistently relate to cognitive aspects (Tropp \& Pettigew, 2005 Study 2). The authors describe this process as one where individuals act as detached observers of outgroup members in general when focused on cognitive dimensions of prejudice. When focused on affective dimensions, individuals tend to respond in terms of emotions and feelings relevant to their relationships with specific outgroup members.

One explanation for this discrepancy is that influencing cognitive dimensions of prejudice such as stereotypes requires perceptions that the person the contact is experienced with is representative of the outgroup (Rothbart \& John, 1985). Contact via friendships often involves processes that highlight individuating information. That is, the outgroup member is viewed as an individual rather than an exemplar of the outgroup (e.g., Rothbart, 1996). This makes cognitive dimensions of prejudice more resistant to change than affective dimensions. Supporting this contention, in one study positive contact produced more favorable group evaluations (affective) but only reduced negative stereotype endorsement when stereotype disconfirming behaviors were perceived as typical of the outgroup (Wolsko, Park, Judd, \& Bachelor, 2003). As such, the picture that emerges is that positive contact influences affective prejudice in a simple manner. Good experiences beget more generous affective evaluations of outgroup members. However, 
changes in cognitions require the perception that the outgroup member is typical of group members in general. Taken together these findings suggest that acquaintance and friendship contact, through their focus on affective ties to outgroup members, primarily shift affective prejudice and that cognitive prejudice remains relatively resistant to change following most positive contact experiences.

Negative intergroup contact. Work conducted from an intergroup threat theory perspective commonly defines negative contact as involving experiences such as being belittled, intimidated, or insulted by an outgroup member. Several studies examined relationships between negative contact experiences and affective dimensions of prejudice. Broadly, this work finds that negative contact experiences relate to less favorable affective reactions to outgroups. For example, in a large scale study of Whites attitudes toward African Americans and African Americans attitudes toward Whites, negative contact experiences related to more negative feelings toward the outgroup (W. G. Stephan et al., 2002).

With regard to cognitive dimensions of prejudice, negative contact also related to greater stereotyping across several contexts including women’s stereotypes about men (C.W. Stephan et. al., 2000), Whites’ stereotypes of Native Canadians (Corenblum \& Stephan, 2001), and Whites' and Blacks' stereotypes of one another (W. G. Stephan et al., 2002). Taken together, these studies suggest that negative contact relates to both affective and cognitive dimensions of prejudice.

\section{Differential relationships between positive/negative intergroup contact and}

affective/cognitive dimensions of prejudice. Although both negative and positive contact are widely studied, only a few studies examined both forms of contact. One study found that negative contact was a stronger predictor of several measures of cognitive dimensions of 
prejudice (e.g., Modern Racism) than was positive contact (Barlow et al., 2012). Similarly, a study that included measures of positive and negative contact as well as measures of cognitive (stereotypes) and affective (feelings and emotions) dimensions of prejudice found both forms of contact related similarly to affective measures of prejudice. However, positive contact experiences were unrelated to negative stereotypes whereas negative contact experiences related to stronger negative stereotype endorsement (Aberson \& Gaffney, 2009). These findings suggest that cognitive dimensions of prejudice relate more strongly to negative experiences with outgroups members than to positive experience such as friendships.

One explanation for differential effects is that negative contact increases the salience of group memberships more than positive contact. Supporting this proposition, participants who experienced negative contact with an ethnic outgroup member were more likely to mention outgroup status (e.g., described contact partners as outgroup members) than were participants who had a positive contact experience. The authors replicated these findings in a second experiment where young participants had either a positive or a negative interaction with an older person (Paolini, Harwood, \& Rubin, 2010). With regard to negative contact experiences, it seems reasonable that negative experiences are more likely than positive to lead to stereotype consistent perceptions. For example, common stereotypes of African Americans include aggressive and arrogant. A negative encounter (e.g., being insulted or intimidated) is consistent with those stereotypes and likely strengthens their endorsement. Additionally, many negative experiences occur in situations that are involuntary and threatening (Pettigrew \& Tropp, 2011) and negative contact experience relate to expectations that future contact will be negative (Gómez, Tropp, \& Fernández, 2011). These findings suggest that negative experiences likely play against 
personalization as an aversive experience promotes avoidance of the offending outgroup member(s) rather than sustained contact.

Focusing on positive contact, there is also evidence that the relationship between positive contact and more favorable evaluations is strongest when category salience is high. For example, in a study of Italians' attitudes toward African Immigrants, positive contact related more strongly to positive feelings (i.e., affective dimension of prejudice) when group membership salience was high. The relationship between contact and positive feelings was significant but substantially smaller when salience was low (Voci \& Hewstone, 2003, Study 1). Another study found that category salience of outgroup members from other countries similarly moderated the relationship between contact and desire to live in the target outgroup’s country (Brown, Vivian, \& Hewstone, 1999).

Although greater salience strengthens contact-prejudice relationships, it appears that salience is consistently stronger for negative contact experiences. Negative contact with an outgroup member is more likely seen as typical of the outgroup than positive contact and promotes negative cognitive evaluations that generalize to the outgroup as a whole (e.g., Wolsko et al., 2003). Positive contact relates to reduced prejudice, but the effect is comparatively weaker than the negative contact-prejudice relationship unless the salience of group membership is high.

Are positive and negative intergroup contact distinct constructs? It is tempting to believe that positive contact and negative contact experiences are simply two sides of the same coin. However, the constructs appear weakly related. In one study, factor analyses of scales including measures of both forms of contact demonstrate the presence of independent constructs and negligible correlations between the two measures (Aberson \& Gaffney, 2008; $r=-.05$ ). Other studies find significant but relatively small correlations between the constructs $(r=-.26$ in 
Barlow et al., 2012; $r=-.18$ in Pettigrew, 2008). Conceptually, it seems reasonable that an individual might have friendships or other positive relationships with outgroup members, but also have negative experiences with other outgroup members.

Summary. The research discussed in this section suggests that positive and negative contact experiences are distinct constructs and that both are important to understanding prejudice. However, limitations to previous work prevent a complete understanding of contactprejudice relationships. First, the bulk of research on contact-prejudice relationships focuses on positive aspects of contact that promote favorable evaluations. Second, the most extensive work addressing both cognitive and affective dimensions of prejudice focused on positive but not negative contact experiences. Third, studies addressing both positive and negative contact did not examine differences between affective and cognitive dimensions of prejudice. In line with calls for a focus on how contact leads to negative effects (e.g., Pettigrew, 2008), the present study employs measures of negative contact as well as positive contact. Additionally, the current work includes measures of affective and cognitive dimensions of prejudice.

\section{Intergroup Threat}

Given the relationship between contact and prejudice, it is important to address factors that mediate the contact-prejudice relationship and whether mediation of this relationship differs depending on valence of contact or dimension of prejudice. In the present study, I focus on the role of intergroup threats as mediators of these relationships. Intergroup threat theory posits that threats to the ingroup promote negative evaluations of outgroups (W. G. Stephan \& Stephan, 2000). The most recent version of the theory defines threats as either realistic (perceived barriers to ingroup welfare) or symbolic (threats to ingroup values). 
The link between threats and affective dimensions of prejudice is well established. Most work focusing on ITT employs affective measures focused on favorability of outgroups and finds substantial relationships between threat and affective dimensions of prejudice across a wide range of samples including reactions to immigrants in the U.S., Spain, and Israel (Bizman \& Yinon, 2001; W. G. Stephan, Diaz-Loving, \& Duran, 2000; W. G. Stephan, Ybarra, \& Bachman, 1999; W. G. Stephan, Ybarra, Martinez, Schwarzwald, \& Tur-Kaspa, 1998).

There is also considerable evidence that threats relate to cognitive dimensions of prejudice. For example, studies demonstrate correlations between threat and negative stereotyping in samples of White Americans evaluating African Americans (Aberson \& Gaffney, 2008), Dutch adolescents’ evaluations of Muslims (González, Verkuyten, Weesie, \& Poppe, 2008), evaluations of people with cancer and AIDS (Berrenberg, Finlay, Stephan, \& Stephan, 2002), and beneficiaries of affirmative action (Renfro, Duran, Stephan, \& Clason, 2006). Similarly, a meta analyses covering 16 studies employing realistic threat measures and 23 studies employing symbolic threat measures, found substantial relationship (rs .35 to .37) between threats and negative stereotypes (Riek, Mania, \& Gaertner, 2006). More generally, threating stimuli reduces executive control (e.g., Lindström \& Bohlin, 2012). When executive functioning is limited, reliance on automatic biases, such as negative stereotypes, increases (Payne, 2005). In the context of the present study, this suggests that intergroup threats promote cognitive dimensions of prejudice such as endorsement of negative stereotypes.

Intergroup threats as mediators of contact-prejudice relationships. Although there is substantial evidence for the relationship between threat and prejudice, evidence for the proposition that intergroup threat, in terms of symbolic and realistic threat, mediates contactprejudice relationships is less well established. Focusing on affective dimensions of prejudice, a 
large scale study examining African American and Whites' attitudes toward each other, symbolic and realistic intergroup threats mediated the relationship between negative contact and feelings toward the outgroup (W. G. Stephan et al., 2002). However, another study examining ProtestantCatholic relationships in Northern Ireland found that symbolic but not realistic threat mediated the positive contact-feeling relationship (Tausch, Tam, Hewstone, Kenworthy, \& Cairns, 2007). Others found no evidence that threats mediated contact-prejudice relationships. For example, studies examining Hindu-Muslim relations in India (Tausch, Hewstone, \& Roy, 2009) and work on a different a Northern Ireland sample found neither symbolic or realistic threat mediated the positive contact-affective prejudice relationship (Tausch, Hewstone, Kenworthy, Cairns, \& Christ, 2007).

Although some of these studies appear to provide conflicting evidence, a closer examination and reanalysis of the data provides a methodological explanation for the absence of mediated effects and greater support for mediation. The two studies finding no effects (Tausch, Hewstone et al., 2007; Tausch et al., 2009) used complex models involving eight variables with relatively small sample sizes for such techniques ( $n s=87$ and 235$)$. These small sample sizes afford limited power to detect effects in complex models. Reanalysis of data from both studies, using a simplified approach with only contact quality, realistic and symbolic threat, and feelings in the model paints a different picture. In the Northern Ireland study (Tausch, Hewstone et al., 2007) reanalysis indicated that symbolic threats significantly mediated the contact-feelings relationship. A similar reanalysis of the India data (Tausch et al., 2009) revealed marginally significant mediation of the contact-feelings relationship by realistic threat. ${ }^{1}$

Few studies examined the mediating role of threats on the relationship between contact and cognitive dimensions of prejudice. However, there is some evidence for the mediation. For 
example, in work focused on evaluations of homosexuals, symbolic threats such as threats to family and national values mediated the relationship between positive contact and beliefs about homosexuals (albeit only addressed for high authoritarian and highly identified heterosexuals; Hodson, Harry, \& Mitchell, 2009). Additional evidence comes from two studies that measured stereotypes but did not test for mediation of the contact-stereotype relationship. A reanalysis of data from a series of studies on women's attitudes toward men (C. W. Stephan, Stephan, Demitrakis, Yamada, \& Clason, 2000), found that symbolic threat mediated the relationship between negative contact and stereotypes of men in two of three samples. Similarly, reanalysis of data from a study of White and Native Canadian's attitudes toward each other (Corenblum \& Stephan, 2001) found that symbolic threat significantly mediated the negative contact-stereotype relationship for Whites and the combined effect of both threats significantly mediated the relationship for Native Canadians.

Strength of mediated effects. The final question addressed by this study is whether differences exist in the strength of mediated effects for negative contact-prejudice relationships compared to positive contact-prejudice relationships. Consistent with the proposition that negative contact experiences are more likely than positive contact to increase group salience (Paolini et al., 2010) and promote perceptions that the contact target is typical of the outgroup (e.g., Wolsko et al., 2003), I expect that negative contact relates more strongly to intergroup threat than does positive contact. In mediation terms, this means that negative contact relates more strongly to the threat-based mediators than does positive contact. Statistically, a mediated effect is the product of the predictor (contact)-mediator (threat) relationship and the mediatoroutcome relationship (prejudice). As the mediator-outcome relationship is the same for any particular outcome variable, differences in the strength of the mediated effect come entirely from 
the predictor-mediator relationship. More simply, if the relationship between one form of contact and threat is stronger than the other, the mediated effect will be stronger.

Summary. Perceptions of threat predict both affective and cognitive dimensions of prejudice. However, there are several limitations in previous investigations of the role of threats in mediating the contact-prejudice relationship. First, there are no investigations focused on whether threats more strongly mediate positive contact-prejudice or negative contact-prejudice relationships. Second, little evidence exists regarding whether threats more strongly mediate contact-affective dimensions of prejudice or contact-cognitive dimensions of prejudice relationships. Finally, no work addresses whether symbolic or realistic threat more strongly mediates contact-prejudice relationships. The present study provides a detailed exploration of the role of threat in mediating contact-prejudice relationships.

\section{Hypotheses}

Hypothesis 1a. Positive contact relates negatively to affective dimensions of prejudice. Hypothesis 1b. Negative contact relates positively to affective dimensions of prejudice. Hypothesis 2. Negative contact predicts cognitive prejudice more strongly than positive contact.

Hypothesis 3. Threats mediate contact-prejudice relationships.

Hypothesis 4. The mediated effect for the negative contact-prejudice relationship is stronger than the mediated effect for the positive contact-prejudice relationship.

\section{Method}

\section{Participants}

Five hundred forty three self-identified White undergraduates from a rural public university in Northern California (USA) participated for extra credit or to fulfill research 
participation requirements. Following data screening detailed below, I deleted four participants, leaving a total sample of 539. This sample consisted primarily of women (71\%) with an average age of $21.0(S D=9.6)$. The majority of students $(72 \%)$ classified their socioeconomic backgrounds as Lower to Middle Class. A sample of 539 yields considerable power (.80) for detecting small standardized regression coefficients $\left(b^{*}=.13\right)$ for analyses examining the effects of contact variables on DVs (Aberson, 2010) and for most situations involving bias-corrected bootstrapped estimates for detecting mediated effects (Fritz \& MacKinnon, 2007). Table 1 presents correlations, means, standard deviations, and reliabilities for study variables.

\section{Contact Measures}

Positive intergroup contact. Six items asked the participant to think about his or her closest African American acquaintance and indicate the extent that contact with that person was perceived as close, equal, voluntary, intimate, pleasant, and cooperative (Islam \& Hewstone, 1993). Participants rated each item on an 11-point scale, with the ends of the scale adapted to each item (e.g., $0=$ completely involuntary to $10=$ completely voluntary). Higher scores indicate contact that is more positive.

Negative intergroup contact. Fourteen items asked participants to indicate the frequency of different negative experiences when interacting with African Americans. Negative experiences included being insulted, harassed, ridiculed, and intimidated. Response options ranged from 0 (never) to 9 (very frequently) with higher scores indicating more negative contact experiences. Items come from W. G. Stephan et al. (2002).

\section{Threat Measures}

Both threat measures correspond to those used in W. G. Stephan et al. (2002). 
Realistic threats. The realistic threat measure included nine items focusing on political and economic threats. Examples of these items include "Blacks dominate American politics more than they should," and “Too much money is spent on educational programs that benefit Blacks.” Responses ranged from 0 (strongly disagree) to 9 (strongly agree). Higher scores indicate greater perceptions of realistic threat.

Symbolic threats. The symbolic threat measure included nine items dealing with belief and value threats. Examples of these items include "Whites and Blacks have very different values” and "Blacks want their rights to be put ahead of the rights of Whites.” Responses ranged from 0 (strongly disagree) to 9 (strongly agree). Higher scores indicate greater perceptions of symbolic threat.

\section{Affective Dimensions of Prejudice}

The present study focuses on positive and negative aspects of feelings and emotions rather than an overall measure that combines positive and negative items. There are two reasons or this approach. The first comes from calls for a focus on how contact leads to negative effects (e.g., Pettigrew, 2008). Examining positive and negative measures separately allows for a clearer picture of how contact relates to negative outcomes. The second reason is that, although correlated substantially, positive and negative items for both feelings and emotions comprise mostly distinct factors. The feeling and emotions measures also come from W. G. Stephan et al. (2002).

Positive and negative feelings. The feeling measures addressed reactions participants felt toward African Americans. Six positive items included admiration, acceptance, affection, approval, sympathy, and warmth. Six negative items included hostility, dislike, superior to, disdain, hatred, and rejection. Items scores ranged from 0 to 9 with scale endpoints differing 
according to item. For example, the hostility items measured ranged from 0 (no hostility at all) to 9 (extreme hostility). Higher scores indicate greater endorsement of each construct. Principal Axis Factoring with Oblimin rotation applied to the 12 items derived two factors explaining $46.7 \%$ of variance with a modest correlation between the factors $(r=.40)$. One factor included negative items (but also strong loadings for two positive items), the second included only positive items. Although two items (acceptance and approval) could reasonably be placed on either factor, they were defined as part of the positive factor for the purpose of the study.

Positive and negative emotions. Ten items addressed how participants would feel when interacting with African American people they did not know. Five items (comfort, confidence, at ease, friendly, and safe) addressed positive emotions and five addressed negative (awkwardness, anxiety, worried, threatened, and nervous) on a ten-point scale $(0=$ not at all to $9=$ extremely $)$. Higher scores indicate greater endorsement of each construct. Principal Axis Factoring with Oblimin rotation derived two factors explaining $56.9 \%$ of the variance in the items. Although the factors correlated strongly $(r=.73)$, the highest loadings for all of the negative items were on one factor and the highest loadings for positive items were on the other factor.

\section{Cognitive Dimensions of Prejudice}

Beliefs and judgments. Participants completed the Pro-Black and Anti-Black scales (Katz \& Hass, 1988). The Pro-Black scale includes ten items focused on obstacles faced by African Americans (e.g., "Black people do not have the same employment opportunities that Whites do”). The Anti-Black scale consists of ten items placing blame on African Americans for poor outcomes (e.g., "Black children would be better off if their parents had better attitudes about learning”). 
Stereotypes. To assess stereotypes, participants indicated the percentage of Blacks who possessed each of 10 traits $(1=0$ to $10 \%$ to $10=90$ to $100 \%)$. The traits included hard working, unintelligent, arrogant, aggressive, modest, ambitious, untrustworthy, insincere, loud, and clannish (W. G. Stephan \& Stephan, 1993). For the scale, higher scores represent greater negative stereotype endorsement.

\section{Results}

\section{Missing Data and Data Screening}

Of the 543 cases, 55 contained missing data. Of those cases, 33 had missing data only a single item. Only 5 cases had more than 20\% missing values with 33\% being the highest missing value. Of the 98 variables, none had more than 3.5\% missing responses. Indicators for the ten stereotyping items had the most missing data, ranging from 14 to 19 cases with missing values on one or more of those items. No other variables had more than $1.5 \%$ missing responses. I used the EM algorithm to estimate values for missing scores. Although techniques such as Maximum Likelihood Regression and Multiple Imputation are preferred for missing data analyses, many of the analyses in the present study do not presently allow for such procedures (e.g., bootstrapping, multiple mediation analyses). In such situations, EM is the recommended single imputation strategy (Bentler, 2006). Although EM may underestimate standard errors and increase Type I error in comparison to Maximum Likelihood or Multiple Imputation, the relatively small proportion of missing data limits these concerns. ${ }^{2}$ Screening for multivariate outliers using the Mahalanobis statistic (criteria for deletion $p<.0005$ ) identified four extreme cases for elimination, leaving 539 cases for analysis.

Following imputation and composite score creation, I examined normality of the distributions of variables. Both contact variables, realistic threat, and the four measures of 
affective dimensions of prejudice showed substantial skew. In several cases, common transformation procedures failed to adequately normalize the distributions. Additionally, preliminary analyses for tests involving several of the affective dependent measures revealed issues with heteroscedasticity. Given these problems, the present analyses employed bootstrapped estimates based on 5,000 samples. Bootstrapped regression does not require that data meet traditional assumptions.

\section{Intergroup Contact and Prejudice}

In this section, I examine the role of positive and negative contact as predictors of cognitive and affective dimensions of prejudice. The primary evidence in this section comes from tests comparing the relative strength of each correlation. That is, I address whether each type of contact predicts each prejudice measure and whether positive contact-prejudice and negative contact-prejudice correlations differ from one another. Before turning to those analyses, it is important to note that positive and negative forms of contact were unrelated $(r=-.01)$.

Intergroup contact and affective dimensions of prejudice. As shown in Table 1 and consistent with Hypotheses $1 \mathrm{a}$ and $1 \mathrm{~b}$, more positive contact and less negative contact related to less affective prejudice. Tests comparing the strength of the correlations found both forms of contact similarly predictive of positive feelings, $t(536)=1.01, p=.31$, negative feelings, $t(536)=$ $1.19, p=.23$, positive emotions, $t(536)=1.08, p=.28$, and negative emotions, $t(536)=0.02, p=$ .99. These tests compare dependent correlations (i.e., the tests account for the positive contactnegative contact correlation; Williams, 1959) and are equivalent to test comparing the regression coefficients from the first step of each model in Table 2. The sections that follow employ the same technique. 
Intergroup contact and cognitive dimensions of prejudice. As shown in Table 3, positive contact significantly predicted Anti-Black beliefs and stereotypes whereas negative contact related to more prejudice on all three measures. Negative contact experiences were stronger predictors of Anti-Black beliefs, $t(536)=4.45, p<.001$ and Stereotyping, $t(536)=1.98$, $p=.048$, but not Pro-Black beliefs, $t(536)=1.43, p=.15)$. Findings do not support predictions for the Pro-Black measure, likely because neither form of contact related strongly to that measure. In general, these findings provide some support for Hypothesis 2, suggesting that negative contact experiences are better predictors of cognitive dimensions of prejudice than positive contact experiences.

\section{Threats as Mediators of the Contact-Prejudice Relationship}

As shown in Table 4 and consistent with Hypothesis 3, threats significantly mediated all of the contact-prejudice relationships (see rows labeled “Total Mediated”). Turning to the individual impact of each mediator, symbolic threats significantly mediated 12 of 14 possible relationships and realistic eight of 14 . Although these effects may appear inconsistent, it is important to recognize there is considerable overlap among the mediators. A mediator that would be significant in a simpler design (e.g., one with a single mediator) may not reach significance in the multiple mediator model. In testing mediators individually, the number of significant mediation relationships rose to 24 of a possible 28. These results provide consistent support for the role of threats in mediating contact-prejudice relationships.

Strength of mediation. Contrasts comparing the relative strength of mediators determined if mediation differed depending on predictor variable (positive or negative contact). Consistent with Hypothesis 4, threat variables (as a set) more strongly mediated the negative contact-prejudice relationship than the positive contact-prejudice across all measures (see Table 
5). These results suggest that threats are more relevant to negative contact experiences. As for each analysis, the relationships between the mediator of interest and prejudice is the same, these differences suggest the negative contact-threat relationship is stronger than the positive contactthreat link. Comparisons of correlations using the technique described earlier support this proposition with for both realistic threat, $t(536)=3.72, p<.001$ and symbolic threat, $t(536)=$ 7.97, $p<.001$. Another set of analyses addressed whether symbolic or realistic threat more strongly mediated each relationship. These analyses (summarized in Table 4, rows labeled “Contrast: Realistic vs. Symbolic”) indicate when differences did exists, symbolic threats tended to be the strongest mediator.

\section{Discussion}

The present study examined how different forms of contact predict affective and cognitive dimensions of prejudice and how intergroup threats mediate these relationships. The major findings were that both positive and negative contact predicted most measures of prejudice; negative contact predicted cognitive dimensions of prejudice more strongly than did positive contact; threats mediated contact-prejudice relationships; and threats more strongly mediated relationships between negative contact and prejudice (compared to mediated relationships between positive contact and prejudice).

\section{Differential Prediction of Cognitive but not Affective Dimensions of Prejudice}

Positive contact related to less prejudice on affective measures whereas negative contact related to more prejudice on affective dimensions of prejudice. The strength of these relationships were similar, suggesting that both positive and negative contact are equally predictive of affective dimensions of prejudice. Consistent with Hypothesis 2, negative contact related more strongly than positive contact to cognitive dimensions of prejudice (on two of three 
measures). This finding is consistent with the proposition that negative contact relates to cognitive dimensions of prejudice toward outgroup members whereas positive contact does not (or does less strongly and only under certain conditions).

Earlier work (Tropp \& Pettigrew, 2005; Study 2) suggested that contact effects generalized most consistently to affective dimensions of prejudice. The present findings suggest this is true only for positive contact experiences. When contact is negative or unpleasant, there appears to be a generalization to both affective and cognitive dimensions of prejudice toward the outgroup. Although it is tempting to conclude that positive contact is unrelated to cognitive dimensions of prejudice, it is important to note that positive contact experiences did relate to reduced prejudice on two of the cognitive measures. More broadly, meta analytic results show some relationship between positive contact and cognitive dimensions of prejudice (Tropp \& Pettigrew, 2005; Study 1). This suggests that positive contact can play a role in reducing cognitive dimensions of prejudice but not as consistent a role as negative contact. The authors of this work speculated that when focused on cognitive dimensions of prejudice, we act as detached observers of outgroup members in general but respond in terms of emotions and feelings relevant to relationships with specific outgroup members when focused on affective dimensions. Although the present results are consistent with those propositions, it is important to recognize that both their findings and those of the present study focused primarily on positive contact defined in terms of personalized relationships (e.g., friendships) with outgroup members. These differences may promote a lack of category salience as the focus of the measurement is on an individual outgroup member rather than outgroup members in general.

Results from work establishing the positive-negative asymmetry effect and the saliencevalence effect offset some of the concerns regarding the focus on personalized positive contact. 
In a series of experiments where participants interacted with a confederate, negative contact conditions consistently produced stronger category salience than did positive contact experiences (termed the salience-valence effect; Paolini et al., 2010). This finding somewhat limits the concern based on the personalized contact measure, as it appears that a more general positive contact measure would similarly limit category salience. Additionally, the present results regarding cognitive aspects of prejudice are consistent with studies addressing the positivenegative asymmetry effect wherein negative contact consistently demonstrated stronger relationships with several measures of prejudice than did positive contact (Barlow et al., 2012). Although that work did not make the distinction between cognitive and affective dimensions of prejudice, the majority of scales utilized (e.g., modern racism, old-fashioned racism, and issue avoidance; Study 2) fit the present study’s definition of cognitive dimensions of prejudice.

\section{Mediation of Intergroup Contact-Prejudice Relationships}

In line with intergroup threat theory and supporting Hypothesis 3, threats consistently mediated contact-prejudice relationships. For every relationship examined, threats significantly mediated the link between contact and prejudice. This suggests that feelings of threat are important regardless of the type of contact experience or dimension of prejudice investigated.

Consistent with Hypothesis 4, stronger mediated effects existed for negative contactprejudice relationships than for positive contact-prejudice. The larger mediated effects for negative contact-prejudice relationships exist because negative contact related more strongly to increased threat than positive contact related to reduced threat. Broadly, this suggests that negative contact experiences are more relevant to threat than positive contact. Positive contact experiences do relate to reduced threat but the magnitude of the relationship is smaller than the relationship between negative contact and increased threat. 
Differences between the strength of mediated effects when comparing realistic and symbolic threats emerged for 10 of the 14 relationships with symbolic threat serving as the stronger mediator in most cases. Additionally, in several cases, symbolic threats were stronger predictors of prejudice than realistic threat. In contrast, other work finds realistic threats more strongly related to White's prejudice against African Americans when using an affective measure of prejudice (Stephan et al., 2002). The different effects of realistic vs. symbolic threat may reflect differences in the samples of these studies. The present sample is students from a campus that serves a small proportion of African American students (less than 5\%). Participants in the Stephan et al. (2002) study came from campuses that were substantially more diverse. Our sample reflects a group of White students who likely had less opportunity for contact with African Americans, making realistic threats less relevant. These findings highlight the complex and situation dependent role for threats (e.g., Cottrell \& Neuberg, 2005) and suggest different threat effects based on the form of prejudice addressed and the groups studied.

\section{Implications}

Study results have two primary implications. First, the effects of positive contact appear less strongly related to cognitive dimensions of prejudice than does negative contact. One explanation for this discrepancy is that negative contact experiences are more likely than positive experiences to make group identity salient (Paolini et al., 2010). Influencing cognitive dimensions of prejudice such as stereotypes requires perceptions that the outgroup target represents the outgroup (i.e., their group identity is salient; Rothbart \& John, 1985). Positive contact experiences may reduce cognitive dimensions of prejudice, but only to the extent that group identity is salient (Hewstone, 2000). Given this information, approaches such as intergroup dialogues (e.g., Nagda \& Zúñiga, 2003) that focus on differences between groups 
(i.e., make group membership salient) appear promising in promoting reduction of both affective and cognitive prejudice.

Threats appear to play a substantial role in explaining contact-prejudice relationships for both affective and cognitive dimensions of prejudice. This suggests that a focus on reducing feelings of threat is a promising approach for promoting prejudice reduction, particularly among individuals who experienced negative outgroup contact. Interventions that target perceptions of realistic and symbolic threat will be more effective than interventions that do not address threat (Al Ramiah \& Hewstone, 2013).

\section{Limitations}

The present results are limited in several manners. The most prominent limitation is the content of the two contact measures. The positive contact scale addressed individualized contact with the closest African American acquaintance whereas the negative contact scale focused on interactions with African Americans in general. Negative contact relates to greater category salience (Paolini et al., 2010) and greater category salience contributes to stronger contactprejudice relationships (e.g. Rothbart \& John, 1985). The individualized nature of the positive contact measure potentially limited category salience and in turn may have limited the strength of the observed positive contact-prejudice relationships. Another issue is that the negative contact measure addressed extreme aspects of negative contact such as being harassed or intimidated. Differences in the forms of the positive and negative contact measures may explain the differential relationships between each form of contact and the prejudice measures. Additional work could clarify whether use of positive and negative contact scales that both focus on general and less extreme forms of contact produces similar findings. 
Another issue is the range of mediating variables considered. This study focused on realistic and symbolic threat, however there are other effective mediators of contact-prejudice relationships. For example, empathy is an established mediator of positive contact-prejudice relationship (Pettigrew \& Tropp, 2008) and individual-level threats such as self-esteem and identity threat are proposed mediators in intergroup threat theory (W. G. Stephan et al., 2009). Mediating variables often relate to unobserved variables that influence the dependent variable, leading to an incomplete picture of mediated effects (Bullock, Green, \& Ha, 2010). For this reason, inclusion of a broader range of mediators may further highlight differences in how different forms of contact relate to cognitive and affective dimensions of prejudice. Also, several measures demonstrated mediocre reliability. Poor reliability tends to attenuate observed effects. Of particular concern is the reliability of the positive contact measure. It may be that some of the differences in observed relationships result from differential reliability as the negative contact variable demonstrated substantially stronger reliability than the positive contact measure.

Another issue involves the content of the threat and prejudice measures. For example, items from the threat (e.g., "Too much money is spent on educational programs that benefit Blacks”) and the Anti-Black scale (e.g., “On the whole, Black people don’t stress education and training”) are similar to items in modern racism scales (e.g., Symbolic Racism 2000, Henry \& Sears, 2002). This suggests the relationships between these measures might result because the scales address a more general construct of modern prejudice. This concern is somewhat reduced by the consistency of relationships with other cognitive dimensions of prejudice (e.g., stereotypes). The convenience sample of college students is also a concern. College students generally have limited opportunities for contact in settings outside of school (e.g., workplace). Relationships between contact, threat, and prejudice might be different for an older sample. 
Finally, as with any correlational study, the present work does not establish a causal role for any of the predictors or mediators.

\section{Conclusions}

This work was the first to address, in the same study, positive and negative contact relationships with both affective and cognitive dimensions of prejudice. Additionally, the work provides a detailed examination of the role of realistic and symbolic threat as mediators of contact-prejudice relationships. Both positive and negative contact experiences predicted most measures of affective and cognitive dimensions of prejudice, however negative contact was the stronger predictor of cognitive dimensions of prejudice. Threats consistently mediated contactprejudice relationships across different forms of contact and different dimensions of prejudice, with the negative contact-prejudice relationship more strongly mediated than the positive contact-prejudice relationship. These results suggest an important role for threats in understanding and potentially reducing both cognitive and affective dimensions of prejudice, particularly when focused on the impact of negative contact experience. 


\section{References}

Aberson, C. L. (2010). Applied power analysis for the behavioral sciences. New York: Routledge.

Aberson, C. L., \& Gaffney, A. M. (2009). An integrated threat model of implicit and explicit attitudes. European Journal of Social Psychology, 39, 808-830. doi: 10.1002/ejsp.582

Allport, G. W. (1954). The nature of prejudice. Reading, MA: Addison-Wesley.

Al Ramiah, A., \& Hewstone, M. (2013). Intergroup contact as a tool for reducing, resolving, and preventing intergroup conflict: Evidence, limitations, and potential. American Psychologist, 68, 527-542. doi: 10.1037/a0032603

Barlow, F. K., Paolini, S., Pedersen, A., Hornsey, M. J., Radke, H. R. M., Harwood, J., ... Sibley, C. G. (2012). The contact caveat: Negative contact predicts increased prejudice more than positive contact predicts reduced prejudice. Personality and Social Psychology Bulletin, 38, 1629-1643. doi: 10.1177/0146167212457953

Bentler, P. M. (2006). EQS 6 structural equations program manual. Encino, CA: Multivariate Software, Inc.

Berrenberg, J. L., Finlay, K. A., Stephan, W. G., \& Stephan, C. W. (2002). Prejudice toward people with cancer or AIDS: Applying the integrated threat model. Journal of Applied Biobehavioral Research, 7, 75-86. doi: 10.1111/j.1751-9861.2002.tb00078.x

Bizman, A., \& Yinon, Y. (2001). Intergroup and interpersonal threats as determinants of prejudice: The moderating role of in-group identification. Basic and Applied Social Psychology, 23, 191-196. doi: 10.1207/153248301750433669 
Brown, R., Vivian, J., \& Hewstone, M. (1999). Changing attitudes through intergroup contact: The effects of group membership salience. European Journal of Social Psychology, 29, 741764. doi: 10.1002/(SICI)1099-0992(199908/09)29:5/6

Bullock, J. G., Green, D. P., \& Ha, S. E. (2010). Yes, but what's the mechanism? (don’t expect an easy answer). Journal of Personality and Social Psychology, 98, 550-558. doi: 10.1037/a0018933

Corenblum, B., \& Stephan, W. G. (2001). White fears and native apprehensions: An integrated threat theory approach to intergroup relations. Canadian Journal of Behavioural Science, 33, 251-268. doi: 10.1037/h0087147

Cottrell, C. A., \& Neuberg, S. L. (2005). Different emotional reactions to different groups: A sociofunctional threat-based approach to "prejudice". Journal of Personality and Social Psychology, 88, 770-789. doi: 10.1037/0022-3514.88.5.770

Davies, K., Tropp, L. R., Aron, A., Pettigrew, T. F., \& Wright, S. C. (2011). Cross-group friendships and intergroup attitudes: A meta-analytic review. Personality and Social Psychology Review, 15, 332-351. doi: 10.1177/1088868311411103

Fritz, M. S., \& MacKinnon, D. P. (2007). Required sample size to detect the mediated effect. Psychological Science, 18, 233-239. doi: 10.1111/j.1467-9280.2007.01882.x

Gómez, A., Tropp, L. R., \& Fernández, S. (2011). When extended contact opens the door to future contact: Testing the effects of extended contact on attitudes and intergroup expectancies in majority and minority groups. Group Processes \& Intergroup Relations, 14, 161-173. doi: 10.1177/1368430210391119 
González, K. V., Verkuyten, M., Weesie, J., \& Poppe, E. (2008). Prejudice towards muslims in the Netherlands: Testing integrated threat theory. British Journal of Social Psychology, 47, 667-685. doi: 10.1348/014466608X284443

Henry, P. J., \& Sears, D. O. (2002). The symbolic racism 2000 scale. Political Psychology, 23, 253-283. doi: 10.1111/0162-895X.00281

Hewstone, M. (2000). Contact and categorization: Social psychological interventions to change intergroup relations. Stereotypes and prejudice: Essential readings. (pp. 394-418) Psychology Press, New York, NY.

Hodson, G., Harry, H., \& Mitchell, A. (2009). Independent benefits of contact and friendship on attitudes toward homosexuals among authoritarians and highly identified heterosexuals. European Journal of Social Psychology, 39, 509-525. doi: 10.1002/ejsp.558

Islam, R. M., \& Hewstone, M. (1993). Dimensions of contact as predictors of intergroup anxiety, perceived out-group variability, and out-group attitude: An integrative model. Personality and Social Psychology Bulletin, 19, 700-710. doi: 10.1177/0022022100031002006

Katz, I., \& Hass, R. G. (1988). Racial ambivalence and American value conflict: Correlational and priming studies of dual cognitive structures. Journal of Personality and Social Psychology, 55, 893-905. doi: 10.1037/0022-3514.55.6.893

Lindström, B. R., \& Bohlin, G. (2012). Threat-relevance impairs executive functions: Negative impact on working memory and response inhibition. Emotion, 12, 384-393. doi: 10.1037/a0027305

Muthén, L. K., \& Muthén, B. O. (1998-2011). Mplus user's guide (6 ${ }^{\text {th }}$ ed). Los Angeles, CA: Muthén \& Muthén. 
Nagda, B. A., \& Zúñiga, X. (2003). Fostering meaningful racial engagement through intergroup dialogues. Group Processes and Intergroup Relations, 6, 111-128. doi: $10.1177 / 1368430203006001015$

Paolini, S., Harwood, J., \& Rubin, M. (2010). Negative intergroup contact makes group memberships salient: Explaining why intergroup conflict endures. Personality and Social Psychology Bulletin, 36, 1723-1738. doi: 10.1177/0146167210388667

Payne, B. K. (2005). Conceptualizing control in social cognition: How executive functioning modulates the expression of automatic stereotyping. Journal of Personality and Social Psychology, 89, 488-503. doi: 10.1037/0022-3514.89.4.488

Pettigrew, T. F. (2008). Future directions for intergroup contact theory and research. International Journal of Intercultural Relations, 32, 187-199. doi: 10.1016/j.ijintrel.2007.12.002

Pettigrew, T. F., \& Tropp, L. R. (2006). A meta-analytic test of intergroup contact theory, Journal of Personality and Social Psychology, 90, 751-783. doi: 10.1037/00223514.90.5.751

Pettigrew, T. F., \& Tropp, L. R. (2008). How does intergroup contact reduce prejudice? Metaanalytic tests of three mediators, European Journal of Social Psychology, 38, 922-934. doi:http://dx.doi.org/10.1002/ejsp.504

Pettigrew, T. F., \& Tropp, L. R. (2011). When groups meet: The dynamics of intergroup contact Psychology Press, New York, NY.

Preacher, K. J., \& Hayes, A. F. (2008). Asymptotic and resampling strategies for assessing and comparing indirect effects in multiple mediator models. Behavior Research Methods, 40, 879-891. doi: 10.3758/BRM.40.3.879 
Renfro, C. L., Duran, A., Stephan, W. G., \& Clason, D. L. (2006). The role of threat in attitudes toward affirmative action and its beneficiaries. Journal of Applied Social Psychology, 36, 41-74. doi: 10.1111/j.0021-9029.2006.00003.x

Riek, B. M., Mania, E. W., \& Gaertner, S. L. (2006). Intergroup threat and the integrated threat theory: A meta-analytic review. Personality and Social Psychology Review, 10, 336-353. doi: 10.1207/s15327957pspr1004_4

Rothbart, M. (1996). Category-exemplar dynamics and stereotype change. International Journal of Intercultural Relations, 20, 305-321. doi: 10.1016/0147-1767(96)00021-1

Rothbart, M., \& John, O. P. (1985). Social categorization and behavioral episodes: A cognitive analysis of the effects of intergroup contact. Journal of Social Issues, 41, 81-104. doi: 10.1111/j.1540-4560.1985.tb01130.x

Stephan, C. W., Stephan, W. G., Demitrakis, K. M., Yamada, A. M., \& Clason, D. L. (2000). Women's attitudes toward men: An integrated threat theory approach. Psychology of Women Quarterly, 24, 63-73. doi: 10.1111/j.1471-6402.2000.tb01022.x

Stephan, W. G., Boniecki, K. A., Ybarra, O., Bettencourt, A., Ervin, K. S., Jackson, L. A., McNatt, P. S., \& Renfro, C. L. (2002). The role of threats in racial attitudes of blacks and Whites. Personality and Social Psychology Bulletin, 28, 1242-1254. doi:

$10.1177 / 01461672022812009$

Stephan, W. G., Diaz-Loving, R., \& Duran, A. (2000). Integrated threat theory and intercultural attitudes: Mexico and the United States. Journal of Cross-Cultural Psychology, 31, 240-249. doi: 10.1177/0022022100031002006

Stephan, W. G., \& Stephan, C. W. (1993). Cognition and affect in stereotyping: Parallel interactive networks. In D. M. Mackie \& D. L. Hamilton (Eds.), Affect, cognition, and 
stereotyping: Interactive processes in group perception (pp. 111-136). Orlando, FL: Academic Press.

Stephan, W. G., \& Stephan, C. W. (2000). An integrated threat theory of prejudice. In S. Oskamp (Ed.), Reducing prejudice and discrimination (pp. 23-46). Hillsdale, NJ: Erlbaum.

Stephan, W. G., Ybarra, O., \& Bachman, G. (1999). Prejudice toward immigrants. Journal of Applied Social Psychology, 29, 2221-2237. doi: 10.1111/j.1559-1816.1999.tb00107.x

Stephan, W. G., Ybarra, O., \& Martinez, C. M., Schwarzwald, J., \& Tur-Kaspa, M. (1998). Prejudice toward immigrants to Spain and Israel: An integrated threat theory analysis. Journal of Cross-Cultural Psychology, 29, 559-576. doi: 10.1177/0022022198294004

Stephan, W. G., Ybarra, O., \& Morrison, K. R. (2009). Intergroup threat theory. In T. Nelson (Ed.). Handbook of prejudice, stereotyping, and discrimination (pp. 43-60). Psychology Press, New York, NY.

Tausch, N., Hewstone, M., Kenworthy, J., Cairns, E., \& Christ, O. (2007). Cross-community contact, perceived status differences, and intergroup attitudes in northern ireland: The mediating roles of individual-level versus group-level threats and the moderating role of social identification. Political Psychology, 28, 53-68. doi: 10.1111/j.14679221.2007.00551.x

Tausch, N., Hewstone, M., Kenworthy, J. B., Psaltis, C., Schmid, K., Popan, J. R., . . Hughes, J. (2010). Secondary transfer effects of intergroup contact: Alternative accounts and underlying processes. Journal of Personality and Social Psychology, 99, 282-302. doi: 10.1037/a0018553 
Tausch, N., Hewstone, M., \& Roy, R. (2009). The relationships between contact, status and prejudice: An integrated threat theory analysis of Hindu-Muslim relations in India. Journal of Community \& Applied Social Psychology, 19, 83-94. doi: 10.1002/casp.984

Tausch, N., Tam, T., Hewstone, M., Kenworthy, J., \& Cairns, E. (2007). Individual-level and group-level mediators of contact effects in northern ireland: The moderating role of social identification. British Journal of Social Psychology, 46, 541-556. doi:

10.1348/014466606X155150

Tropp, L. R., \& Pettigrew, T. F. (2005). Differential relationships between intergroup contact and affective and cognitive dimensions of prejudice. Personality and Social Psychology Bulletin, 31, 1145-1158. doi: 10.1177/0146167205274854

Voci, A., \& Hewstone, M. (2003). Intergroup contact and prejudice toward immigrants in italy: The mediational role of anxiety and the moderational role of group salience. Group Processes \& Intergroup Relations, 6, 37-52. doi:http://dx.doi.org/ $10.1177 / 1368430203006001011$

Williams, E. J. (1959). The comparison of regression variables. Journal of the Royal Statistical Society, Series B, 21, 396-399. Retrieved from http://www.jstor.org/stable/2983809

Wolsko, C., Park, B., Judd, C. M., \& Bachelor, J. (2003). Intergroup contact: Effects on group evaluations and perceived variability. Group Processes and Intergroup Relations, 6, 93-110. doi: 10.1177/1368430203006001014 


\section{Footnotes}

${ }^{1}$ Reanalysis of these data involved generating a dataset of the correct size using the correlation matrix reported in the article of interest. Next, using SPSS and Indirect (Preacher \& Hayes, 2008), I tested a multiple mediator model using contact, symbolic threat, realistic threat, and the dependent variable of interest. All other variables included in the correlation matrix were excluded from these tests.

${ }^{2}$ To address whether use of EM influenced results, I ran the multiple regression analyses found in Tables 2 and 3 using data subjected to multiple imputation (20 imputed datasets). These data produced results consistent with the EM algorithm. Betas differed by no more than .01 and the pattern of significance was the same across both approaches. 
Table 1

Correlations, Descriptive Statistics, and Reliability for Study Variables

\begin{tabular}{|c|c|c|c|c|c|c|c|c|c|c|c|}
\hline & 1 & 2 & 3 & 4 & 5 & 6 & 7 & 8 & 9 & 10 & 11 \\
\hline 1. Positive Contact & .71 & & & & & & & & & & \\
\hline 2. Negative Contact & -.01 & .94 & & & & & & & & & \\
\hline 3. Realistic Threat & $-.17 *$ & $.30 *$ & .92 & & & & & & & & \\
\hline 4. Symbolic Threat & $-.18^{*}$ & $.44^{*}$ & $.64^{*}$ & .89 & & & & & & & \\
\hline 5. Positive Feelings & $.29 *$ & $-.23 *$ & $-.45 *$ & $-.42 *$ & .78 & & & & & & \\
\hline 6. Negative Feelings & $-.25 *$ & $.31 *$ & $.38 *$ & $.46^{*}$ & $-.45 *$ & .85 & & & & & \\
\hline 7. Positive Emotions & $.33 *$ & $-.27 *$ & $-.22 *$ & $-.32 *$ & $.46^{*}$ & $-.41 *$ & .83 & & & & \\
\hline 8. Negative Emotions & $-.26 *$ & $.26 *$ & $.17 *$ & $.30 *$ & $-.30 *$ & $.43 *$ & $-.69 *$ & .89 & & & \\
\hline 9. Pro Black & .05 & $-.14 *$ & $-.41 *$ & $-.28 *$ & $.39 *$ & $-.13 *$ & .02 & .05 & .80 & & \\
\hline 10. Anti Black & $-.16^{*}$ & $.41^{*}$ & $.49 *$ & $.66^{*}$ & $-.39 *$ & $.41^{*}$ & $-.31^{*}$ & $.27 *$ & $-.24 *$ & .83 & \\
\hline 11. Stereotypes & $-.24 *$ & $.35 *$ & $.41^{*}$ & $.57 *$ & $-.39 *$ & $.42 *$ & $-.34 *$ & $.33 *$ & $-.21 *$ & $.53 *$ & .78 \\
\hline Possible Range & $0-60$ & $0-126$ & $0-81$ & $0-81$ & $0-54$ & $0-54$ & $0-45$ & $0-45$ & $0-50$ & $0-50$ & $10-100$ \\
\hline$M$ & 45.9 & 29.1 & 10.1 & 19.4 & 37.9 & 8.5 & 33.8 & 11.9 & 30.6 & 17.4 & 39.9 \\
\hline$S D$ & 8.4 & 24.0 & 12.5 & 14.5 & 7.5 & 8.5 & 6.6 & 8.6 & 7.9 & 8.3 & 12.7 \\
\hline Skew & -0.8 & 1.0 & 1.5 & 0.8 & -0.3 & 1.0 & -0.3 & 0.4 & -0.2 & 0.2 & 0.3 \\
\hline
\end{tabular}

Note. Standard error of skew is 0.11 . Cronbach's alpha on diagonal. ${ }^{*} p<.05$. 
Table 2

Affective Dimensions of Prejudice Regressed on Contact and Threat

\begin{tabular}{|c|c|c|c|c|c|c|c|c|c|c|c|c|c|c|c|c|}
\hline & \multicolumn{4}{|c|}{ Positive Feelings } & \multicolumn{4}{|c|}{ Negative Feelings } & \multicolumn{4}{|c|}{ Positive Emotions } & \multicolumn{4}{|c|}{ Negative Emotions } \\
\hline & \multicolumn{2}{|c|}{ Step 1} & \multicolumn{2}{|c|}{ Step 2} & \multicolumn{2}{|c|}{ Step 1} & \multicolumn{2}{|c|}{ Step 2} & \multicolumn{2}{|c|}{ Step 1} & \multicolumn{2}{|c|}{ Step 2} & \multicolumn{2}{|c|}{ Step 1} & \multicolumn{2}{|c|}{ Step 2} \\
\hline & $b^{*}$ & $s r^{2}$ & $b^{*}$ & $s r^{2}$ & $b^{*}$ & $s r^{2}$ & $b^{*}$ & $s r^{2}$ & $b^{*}$ & $s r^{2}$ & $b^{*}$ & $s r^{2}$ & $b^{*}$ & $s r^{2}$ & $b^{*}$ & $s r^{2}$ \\
\hline Positive & $.29 *$ & .084 & $.21 *$ & .035 & $-.24 *$ & .060 & $-.17 *$ & .029 & $.32 *$ & .106 & $.29 *$ & .082 & $-.26 *$ & .067 & $-.23 *$ & .051 \\
\hline Negative & $-.23 *$ & .053 & -.07 & .003 & $.31^{*}$ & .098 & $.15^{*}$ & .019 & $-.26^{*}$ & .069 & $-.18 *$ & .027 & $.26 *$ & .067 & $.18 *$ & .027 \\
\hline Realistic & & & $-.29 *$ & .049 & & & $.12 *$ & .009 & & & .00 & .000 & & & -.05 & .002 \\
\hline Symbolic & & & $-.17 *$ & .014 & & & $.28 *$ & .042 & & & $-.18 *$ & .017 & & & $.21 *$ & .023 \\
\hline & & & & & & & & & & & & & & & & \\
\hline$R^{2}$ Change & & & & $.140^{*}$ & & & & $.109 *$ & & & & $.026^{*}$ & & & & $.025^{*}$ \\
\hline$R^{2}$ Total & & $.138 *$ & & $.278^{*}$ & & $.159 *$ & & $.268 *$ & & $.176^{*}$ & & $.202^{*}$ & & $.135 *$ & & $.160^{*}$ \\
\hline
\end{tabular}

Note. Contact variables are entered in the first step. Threats in the second step. The semipartial correlation $\left(s r^{2}\right)$ indicates unique proportion of variance explained by the predictor within the model. ${ }^{*} p<.05$. 
Table 3

Cognitive Dimensions of Prejudice Regressed on Contact and Threat

\begin{tabular}{|c|c|c|c|c|c|c|c|c|c|c|c|c|}
\hline & \multicolumn{4}{|c|}{ Pro-Black } & \multicolumn{4}{|c|}{ Anti-Black } & \multicolumn{4}{|c|}{ Stereotyping } \\
\hline & \multicolumn{2}{|c|}{ Step 1} & \multicolumn{2}{|l|}{ Step 2} & \multicolumn{2}{|c|}{ Step 1} & \multicolumn{2}{|l|}{ Step 2} & \multicolumn{2}{|c|}{ Step 1} & \multicolumn{2}{|c|}{ Step 2} \\
\hline & $b^{*}$ & $s r^{2}$ & $b^{*}$ & $s r^{2}$ & $b^{*}$ & $s r^{2}$ & $b^{*}$ & $s r^{2}$ & $b^{*}$ & $s r^{2}$ & $b^{*}$ & $s r^{2}$ \\
\hline Positive Contact & .05 & .003 & -.01 & .000 & $-.16^{*}$ & .025 & -.05 & .003 & $-.23 *$ & .054 & $-.15^{*}$ & .020 \\
\hline Negative Contact & $-.14 *$ & .020 & -.01 & .000 & $.41^{*}$ & .168 & $.16^{*}$ & .020 & $.35 *$ & .120 & $.14^{*}$ & .015 \\
\hline Realistic & & & $-.40 *$ & .092 & & & $.12 *$ & .008 & & & .06 & .002 \\
\hline Symbolic & & & -.02 & .000 & & & $.50 *$ & .132 & & & $.44^{*}$ & .101 \\
\hline$R^{2}$ Change & & & & $.146^{*}$ & & & $.266^{*}$ & & & & & 180* \\
\hline$R^{2}$ Total & & $.022 *$ & & $.168 *$ & & $.194^{*}$ & $.460 *$ & & & $.176^{*}$ & & $.356^{*}$ \\
\hline
\end{tabular}

Note. Contact variables are entered in the first step. Threats in the second step. The semipartial correlation ( $\left.s r^{2}\right)$ indicates unique proportion of variance explained by the predictor within the model. ${ }^{*} p<.05$. 
Table 4

95\% Confidence Limits for Mediated (Indirect) Effects and Comparisons Between Mediated Effects

\begin{tabular}{|c|c|c|c|c|c|c|c|}
\hline & $\begin{array}{l}\text { Positive } \\
\text { Feelings }\end{array}$ & $\begin{array}{l}\text { Negative } \\
\text { Feelings }\end{array}$ & $\begin{array}{l}\text { Positive } \\
\text { Emotions }\end{array}$ & $\begin{array}{l}\text { Negative } \\
\text { Emotions }\end{array}$ & Pro-Black & Anti-Black & Stereotyping \\
\hline \multicolumn{8}{|l|}{ IV = Positive Contact } \\
\hline Total Mediated & {$[.040, .118]^{*}$} & {$[-.110,-.039]^{*}$} & {$[.013, .062]^{*}$} & {$[-.055,-.010]^{*}$} & {$[.034, .110]^{*}$} & {$[-.156,-.059]^{*}$} & {$[-.130,-.048]^{*}$} \\
\hline $\mathrm{M}=$ Realistic & {$[.020, .084]^{*}$} & {$[-.048,-.004]^{*}$} & {$[-.018, .020]$} & {$[-.007, .030]$} & {$[.032, .109]^{*}$} & {$[-.041,-.004]^{*}$} & {$[-.029, .004]$} \\
\hline M = Symbolic & {$[.010, .058]^{*}$} & {$[-.086,-.025]^{*}$} & {$[.011, .065]^{*}$} & {$[-.069,-.016]^{*}$} & {$[-.016, .025]$} & {$[-.131,-.049]^{*}$} & {$[-.121,-.043]^{*}$} \\
\hline $\begin{array}{l}\text { Contrast: Realistic vs. } \\
\text { Symbolic }\end{array}$ & {$[-.018, .064]$} & {$[-.006, .074]$} & {$[-.077, .001]$} & {$[.015, .091] *_{\mathrm{s}}$} & {$[.023, .118]{ }_{R}$} & {$[.032, .117] *_{\mathrm{s}}$} & {$[.033, .117]^{*} \mathrm{~s}$} \\
\hline \multicolumn{8}{|l|}{ IV = Negative Contact } \\
\hline Total Mediated & {$[-.217,-.112]^{*}$} & {$[.113, .214]^{*}$} & {$[-.128,-.037]^{*}$} & {$[.034, .121]^{*}$} & {$[-.191,-.079]^{*}$} & {$[.197, .316]^{*}$} & {$[.157, .271]^{*}$} \\
\hline $\mathrm{M}=$ Realistic & {$[-.131,-.053]^{*}$} & {$[.004, .074]^{*}$} & {$[-.035, .033]$} & {$[-.052, .014]$} & {$[-.170,-.081]^{*}$} & {$[.007, .068]^{*}$} & {$[-.009, .049]$} \\
\hline $\mathrm{M}=$ Symbolic & {$[-.127,-.026]^{*}$} & {$[.075, .183]^{*}$} & {$[-.139,-.025]^{*}$} & {$[.040, .145]^{*}$} & {$[-.059, .038]$} & {$[.166, .282]^{*}$} & {$[.139, .257]^{*}$} \\
\hline $\begin{array}{l}\text { Contrast: Realistic vs. } \\
\text { Symbolic }\end{array}$ & {$[-.088, .055]$} & {$[.170, .017] *_{\mathrm{S}}$} & {$[.000, .163]$} & {$[.186, .036] *_{\mathrm{s}}$} & {$[.191, .042] *_{\mathrm{R}}$} & {$[.263, .120] *_{S}$} & {$[.251, .107] *_{\mathrm{s}}$} \\
\hline
\end{tabular}

Note. Total Mediated reflects mediation afforded by the combination of Realistic and Symbolic Threat. Values below Total Mediated (noted as $\mathrm{M}=$ ) reflect each mediator's contribution. Comparisons between mediators (e.g. Contrast: Realistic vs. Symbolic) indicate whether one predictor is a stronger mediator than another. For each significant contrast, subscripts (S for symbolic, R for realistic) indicate which was the stronger mediator. General mediation and comparisons between mediators tested using INDIRECT with bias corrected bootstrapped estimates (Preacher \& Hayes, 2008). ${ }^{*} p<.05$. 
Table 5

Comparisons of Strength of Mediation for Positive/Negative Contact - DV Relationships

\begin{tabular}{|c|c|c|c|c|c|c|c|}
\hline Contrast & $\begin{array}{l}\text { Positive } \\
\text { Feelings }\end{array}$ & $\begin{array}{l}\text { Negative } \\
\text { Feelings }\end{array}$ & $\begin{array}{l}\text { Positive } \\
\text { Emotions }\end{array}$ & $\begin{array}{l}\text { Negative } \\
\text { Emotions }\end{array}$ & Pro-Black & Anti-Black & Stereotyping \\
\hline $\begin{array}{l}\text { Positive vs. Negative } \\
\text { Total }\end{array}$ & {$[-.146,-.024]^{*}$} & {$[-.150,-.039]^{*}$} & {$[-.091,-.018]^{*}$} & {$[-.130,-.019]^{*}$} & {$[-.126,-.003]^{*}$} & {$[-.224,-.067]^{*}$} & {$[-.191,-.058]^{*}$} \\
\hline $\begin{array}{l}\text { Positive vs. Negative } \\
\text { Realistic }\end{array}$ & {$[-.084,-.002]^{*}$} & {$[-.048,-.001]^{*}$} & {$[-.019, .018]$} & {$[-.034, .004]$} & {$[-.112,-.002]^{*}$} & {$[-.046,-.001]^{*}$} & {$[-.031, .003]$} \\
\hline $\begin{array}{l}\text { Positive vs. Negative } \\
\text { Symbolic }\end{array}$ & {$[-.089,-.015]^{*}$} & {$[-.123,-.032]^{*}$} & {$[-.099,-.014] *$} & {$[-.103,-.020]^{*}$} & {$[-.037, .023]$} & {$[-.200,-.064]^{*}$} & {$[-.180,-.056]^{*}$} \\
\hline
\end{tabular}

Note. Comparisons address whether mediation is stronger for positive or negative contact on the dependent measure of interest.

Negative values indicate stronger mediation for the negative contact-dv relationship, positive values indicate stronger mediation for the positive contact-dv relationship. In every case where contrasts were significant, negative contact is the stronger mediator. The column noted as Positive vs. Negative Total addresses the combined mediated effect of Realistic and Symbolic Threat. Subsequent columns address mediation by Realistic and Symbolic Threats separately. Comparisons between Positive and Negative contact used bias corrected bootstrapped estimates provided by Mplus (Muthén \& Muthén, 1998-2011). *p<.05. 